AperTO - Archivio Istituzionale Open Access dell'Università di Torino

\title{
REST levels affect the functional expression of voltage dependent calcium channels and the migratory activity in immortalized GnRH neurons
}

\section{This is the author's manuscript}

Original Citation:

Availability:

This version is available http://hdl.handle.net/2318/1584562

since 2017-05-15T12:44:03Z

Published version:

DOI:10.1016/j.neulet.2016.06.050

Terms of use:

Open Access

Anyone can freely access the full text of works made available as "Open Access". Works made available under a Creative Commons license can be used according to the terms and conditions of said license. Use of all other works requires consent of the right holder (author or publisher) if not exempted from copyright protection by the applicable law. 


\section{Accepted Manuscript}

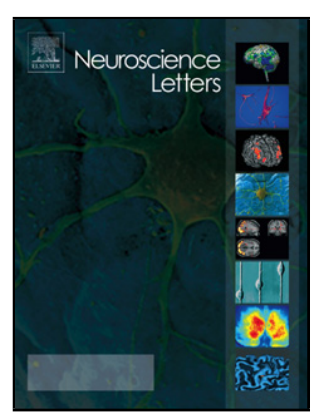

Title: REST levels affect the functional expression of voltage dependent calcium channels and the migratory activity in immortalized GnRH neurons

Author: Susanna Antoniotti Federico Alessandro Ruffinatti Simona Torriano Anna Luganini Rosalba D'Alessandro Davide Lovisolo

PII: S0304-3940(16)30459-1

DOI: http://dx.doi.org/doi:10.1016/j.neulet.2016.06.050

Reference: NSL 32138

To appear in: $\quad$ Neuroscience Letters

Received date: $\quad 31-5-2016$

Accepted date: $\quad$ 23-6-2016

Please cite this article as: Susanna Antoniotti, Federico Alessandro Ruffinatti, Simona Torriano, Anna Luganini, Rosalba D'Alessandro, Davide Lovisolo, REST levels affect the functional expression of voltage dependent calcium channels and the migratory activity in immortalized GnRH neurons, Neuroscience Letters http://dx.doi.org/10.1016/j.neulet.2016.06.050

This is a PDF file of an unedited manuscript that has been accepted for publication. As a service to our customers we are providing this early version of the manuscript. The manuscript will undergo copyediting, typesetting, and review of the resulting proof before it is published in its final form. Please note that during the production process errors may be discovered which could affect the content, and all legal disclaimers that apply to the journal pertain. 
REST levels affect the functional expression of voltage dependent calcium channels and the migratory activity in immortalized GnRH neurons

Susanna Antoniotti ${ }^{\mathrm{a}, \mathrm{b}}$, Federico Alessandro Ruffinatti ${ }^{\mathrm{a} \dagger}$, Simona Torriano $^{\mathrm{a} \dagger \dagger}$, Anna Luganini ${ }^{\mathrm{a}}$, Rosalba D'Alessandro ${ }^{\mathrm{c}}$, Davide Lovisolo ${ }^{\mathrm{a}, \mathrm{b}, \mathrm{d}} *$

${ }^{\mathrm{a}}$ Department of Life Sciences and Systems Biology, University of Torino, via Accademia Albertina 13, 10123, Torino, Italy;

${ }^{\mathrm{b}}$ NIS Centre for Nanostructured Interfaces and Surfaces, University of Torino, Italy;

${ }^{c}$ National Institute for Digestive Diseases De Bellis, via Turi 27, 70013, Castellana Grotte, Bari, Italy;

${ }^{\mathrm{d}}$ Neuroscience Institute of Torino, Italy;

${ }^{\dagger}$ Federico Alessandro Ruffinatti present address: Department of Pharmaceutical Sciences, University of Eastern Piedmont (UPO), Novara, Italy;

${ }^{\dagger}$ Simona Torriano present address: Inserm, Institute for Neuroscience, Montpellier, France.

*Correspondence to: Davide Lovisolo

Department of Life Sciences and Systems Biology

University of Torino

Via Accademia Albertina 13

10123 - Torino - Italy

tel. +39.011 .6704668$

fax +39.011 .6704508$

e-mail: davide.lovisolo@unito.it 


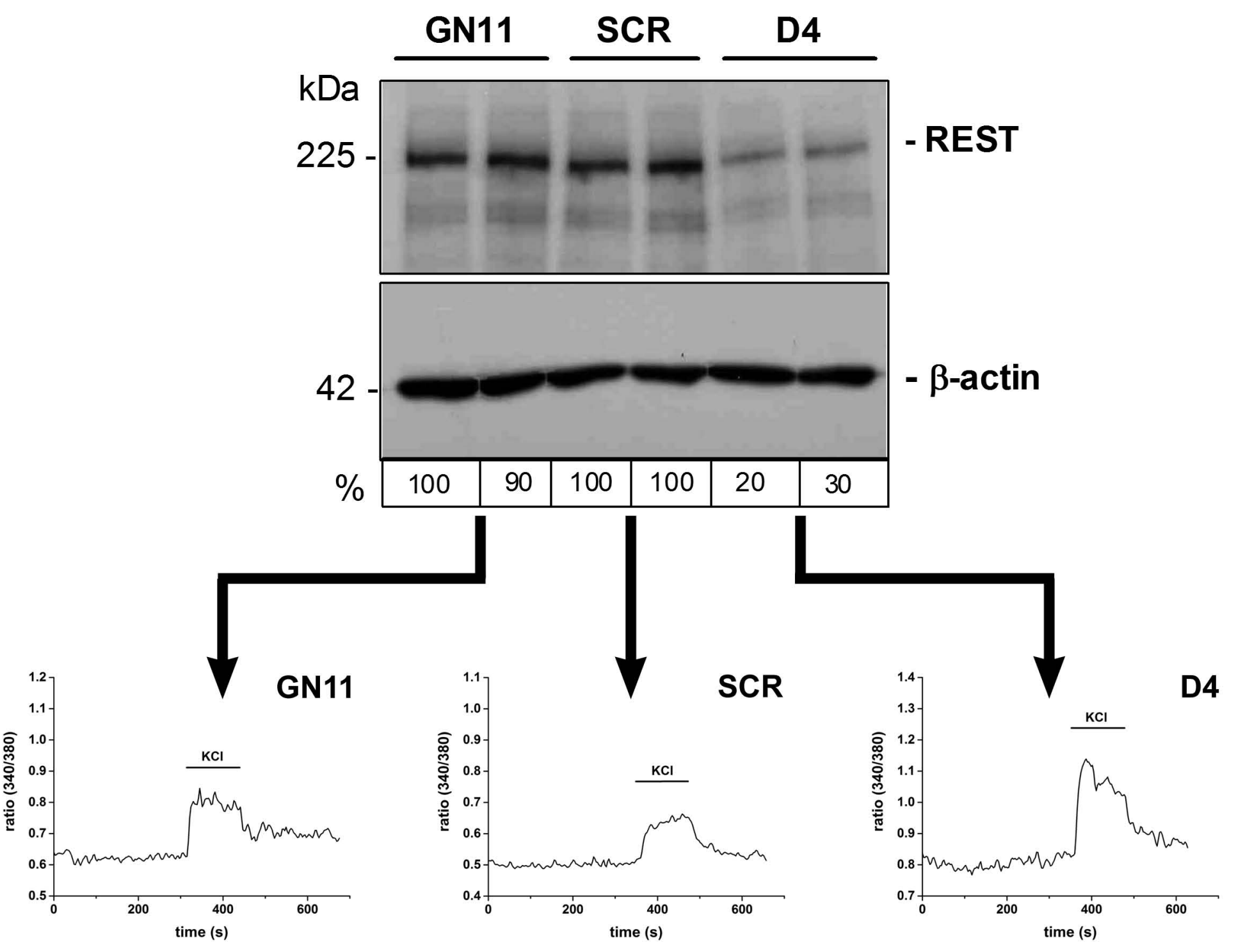


- We downregulated REST transcription factor in neuronal GN11 cell line by silencing. -994-D4 clone, expressing low REST levels, showed a reduced migratory potential.

- REST silencing increased expression of functional voltage-dependent $\mathrm{Ca}^{2+}$ channels.

- Enhancement of depolarization-induced calcium signals is dependent on P/Q channels 


\section{Abbreviations:}

REST/NRSF, repressor element-1 silencing transcription factor/neuron restrictive silencer factor;

VDCCs, voltage dependent calcium channels; GnRH, gonadotropin hormone-releasing hormone. 


\begin{abstract}
The repressor element-1 silencing transcription factor (REST) has emerged as a key controller of neuronal differentiation and has been shown to play a critical role in the expression of the neuronal phenotype; however, much has still to be learned about its role at specific developmental stages and about the functional targets affected. Among these targets, calcium signaling mechanisms are critically dependent on the developmental stage and their full expression is a hallmark of the mature, functional neuron. We have analyzed the role played by REST in GN11 cells, an immortalized cell line derived from gonadotropin hormone releasing hormone $(\mathrm{GnRH})$ neurons at an early developmental stage, electrically non-excitable and with a strong migratory activity. We show for the first time that functional voltage-dependent calcium channels are expressed in wild type GN11 cells; down-regulation of REST by a silencing approach shifts these cells towards a more differentiated phenotype, increasing the functional expression of $\mathrm{P} / \mathrm{Q}$-type channels and reducing their migratory potential.
\end{abstract}

Keywords: REST/NRSF; calcium channels; GnRH neurons; GN11 cells; GT1-7 cells; neuronal migration. 


\section{Introduction}

Since its discovery 20 years ago [1,2], the repressor element-1 silencing transcription factor/neuronrestrictive silencing factor (REST/NRSF) transcriptional repressor has emerged as a key controller of the neuronal phenotype during development [3-6] and also in the adult nervous system [7]. In the latter case several reports have pointed to its involvement in the shift from physiological to pathological conditions. An upregulation of REST in ischemic seizures has been interpreted as a potentially adverse effect, leading to neurodegenerative processes [8,9], even if the relationship between REST levels and silencing of neuronal genes has been reported to be quite complex and specific [10]; on the other hand, the same up-regulation following network hyperexcitation has been shown recently to play a protective role on the function of neuronal circuits [11].

While these findings confirm the relevance of REST in both physiology and pathology, much has still to be learned about its role at specific developmental steps, also because REST null mice die at early embryonic stages [12]. Among the potential functional targets, a relevant role is played by the components of the calcium signaling toolbox. The extent to which REST controls this crucial aspect of the emergence of the neuronal phenotype has been directly investigated only in PC12 cells $[13,14]$. Here we have addressed the issue of the role of REST in the regulation of calcium signalling mechanisms in a more functionally relevant model, immortalized gonadotropin hormone releasing hormone $(\mathrm{GnRH})$ neurons. These neurons arise from the olfactory placode and migrate to their septo-hypothalamic localisation, where they finally differentiate into neurosecretory neurons $[15,16]$. The steps of their development are recapitulated in two immortalised cell lines that have been obtained by genetically targeted tumorigenesis: GN11 cells [17] have been isolated from a murine olfactory bulb tumour; they exhibit an immature neuronal phenotype, with high proliferative and migratory activity, and have been regarded as electrically non-excitable $[18,19]$. In contrast GT1-7 cells [20], obtained from a hypothalamic tumour, represent post-migratory GnRH neurons, and show the relevant properties of a mature phenotype: neurite growth, excitability and hormone release [18].

In the present paper we show that the two lines express different levels of REST; moreover we show that in GN11 cells, in which REST levels are higher, silencing of the repressor causes significant changes in the expression and functionality of voltage dependent calcium channels and a reduction of the migratory activity.

\section{Materials and methods}




\section{Cell culture}

GN11 [17] and GT1-7 [20] cells and their derived clones were plated on plastic dishes (TPP, Techno Plastic Products) and maintained in Dulbecco's Modified Eagle's medium (DMEM) supplemented with $10 \%$ heat-inactivated fetal calf serum (FCS, Lonza), $50 \mu \mathrm{g} / \mathrm{ml}$ gentamycin and 2 $\mathrm{mM}$ glutamine, at $37{ }^{\circ} \mathrm{C}$, in a humidified atmosphere of $5 \% \mathrm{CO}_{2}$ in air. To avoid unspecific effects induced by proliferation, and to allow the appearance of a more differentiated phenotype, for migration assays and calcium imaging experiments cells were serum starved in low serum (1 and $0.5 \%$ FCS respectively).

\section{Transfection}

Two different siRNA sequences against REST and a scrambled sequence have been used. The plasmids, inserted into pcDNA 6.2-GW/EmGFP-miR expression vectors (Invitrogen ${ }^{\mathrm{TM}}$, Life Technologies) to give rise to plasmid shRNA \#1, \#2 and the scrambled control, were the kind gift of Dr D. Pozzi, Humanitas Clinical and Research Center, Milano, Italy (see ref. 11 for details). Details of the silencing protocol are given in the Supplementary Materials.

\section{Immunoblotting experiments}

The monoclonal antibody against REST (a-REST) was obtained from Areta International. Details are given in the Supplementary Materials.

\section{Proliferation assays}

The protocols are described in the Supplementary Materials.

\section{Migration assays}

Cell migration was analyzed by means of a scratch assay, by measuring the distance covered by the migrating cells. For each scratch, the distance between the two sides at different time points was measured and expressed as percentage of the original width (corresponding to 100\%). Only scratches having a width of 430 - $540 \mu \mathrm{m}$ (corresponding to 180 - 230 pixels in the acquired images) were considered. Details of the protocol are given in the Supplementary Materials.

\section{$q R T-P C R$}

The protocols are described in the Supplementary Materials.

$\left[\mathrm{Ca}^{2+}\right]_{i}$ imaging 
$\left[\mathrm{Ca}^{2+}\right]_{\mathrm{i}}$ imaging experiments were performed using the ratiometric fluorescent calcium probe Fura2-acetoxymethyl ester (Fura-2 AM, Life Technologies). Cells were plated on glass coverslips coated with poly-L-lysine $(100 \mu \mathrm{g} / \mathrm{ml})$ at a density of $1 \times 10^{4}$ cells $/ \mathrm{cm}^{2}$ in $10 \%$ FCS DMEM; the following day, medium was changed with 0.5\% FCS DMEM and cells were kept in reduced serum for $24-48 \mathrm{~h}$. The imaging experiments were performed as previously described [13]. Details are given in the Supplementary Materials.

\section{Statistical analysis}

Data are expressed as mean \pm SEM. Unpaired Student's t-test or one-way ANOVA and post-hoc Tukey's tests were performed to evaluate statistically significant differences among groups.

\section{Results}

High level of REST in immortalized GnRH neurons at early differentiation stage GN11 cells represent a model of GnRH neurons at an early differentiation stage, and thus can be likely candidates for the expression of high levels of REST. This was confirmed by immunoblotting experiments, showing a strong expression of the protein. Interestingly, in the more differentiated counterpart, GT1-7 cells, REST levels were significantly lower (31 $\pm 5 \%$ vs GN11 cells, taken as $100 \% ; \mathrm{n}=3, \mathrm{p}<0.05$; unpaired t-test). A representative western blot is shown in Fig. 1A. Based on these findings, we postulated that this difference in REST expression levels could be involved in the regulation of specific differentiation markers; we therefore decided to manipulate GN11 cells by RNA interference to down-regulate REST.

\section{Generation of stable REST knock-down GN11 cells}

All clones incorporating the two shRNAs showed variable amounts of reduction of REST expression. Clone 994-D4, that had integrated sequence \#2, showed the best REST downmodulation compared to controls (GN11 cells and scrambled transfectants): in this silenced clone, REST protein levels were reduced to $20 \pm 4 \%(n=8, p<0.05$, unpaired t-test vs GN11 cells, 100\%). POOL2 containing the scrambled sequence showed REST levels coincident with those of GN11 cells. The 994-D4 clone was therefore used for biological assays; GN11 and POOL2 (thereafter referred to as "scramble") cells were used as reference. A representative immunoblotting experiment is shown in Fig. 1B. 
In all growth conditions, no relevant change in proliferation could be observed in 994-D4 cells as compared to GN11 and scramble cells. A typical experiment reporting the number of cells reached in different conditions at $48 \mathrm{~h}$ is shown in Supplementary Fig. SM 1 and the whole data are presented in the Supplementary Materials, Table SM 2.

\section{REST modulates the migratory rate of GN11 cells}

To understand the role of REST levels in cell motility, we compared migration of GN11 and scramble cells with the 994-D4 clone. Migration was monitored by means of a scratch assay in reduced serum ( $1 \% \mathrm{FCS})$, to rule out a contribution of proliferation to gap closure.

After scratching, cells were allowed to migrate for 8 hours to fill the gap. No significant difference in migration could be observed between GN11 and scramble cells, while a significant ( $\mathrm{p}<0.05$; post-hoc Tukey's test) reduction in migration was observed in the 994-D4 clone at all time points (5 experiments; Fig. 2), pointing to a role of REST in the control of the migratory properties of this cell line. For comparison, migratory activity was also evaluated in GT1-7 cells, considered to show a low migratory potential [18], in the same conditions as above (three experiments; Fig. 2). At all time points, the values were significantly lower than those obtained from the three GN11 lines ( $\mathrm{p}<$ 0.05; post-hoc Tukey's test).

\section{The impact of REST silencing on calcium signalling mechanisms}

We subsequently investigated the impact of REST silencing on a relevant functional parameter that has been shown to play a key role in migratory GnRH neurons [21], the expression of voltage dependent calcium channels (VDCCs). GN11 cells have been described as lacking $\mathrm{Na}^{+}$and $\mathrm{Ca}^{2+}$ voltage dependent channels [18,19]; more recently, however, expression of the transcript of P/Q type VDCCs has been reported [22]. For this reason, we reexamined VDCCs expression and functionality in both control and silenced cells, using a calcium imaging approach.

When cells were chemically depolarized by perfusion with an extracellular solution containing 40 $\mathrm{mM} \mathrm{KCl}$, in GN11 cells the results were at variance with the reported absence of functional VDCCs: an increase in $\left[\mathrm{Ca}^{2+}\right]_{\mathrm{i}}$ was observed (Fig. $\left.3 \mathrm{~A}\right)$ in $41.38 \pm 15.79 \%$ of cells $(232$ cells, 5 experiments; Fig. 3E); the average peak response, $\Delta \mathrm{R} / \mathrm{R}$ was $21.80 \pm 3.16 \%$ (Fig. 3F). A similar picture was obtained from scramble cells (Fig. 3B): the responding cells were $48.05 \pm 10.24 \%$ (256 cells, 6 experiments; Fig. 3E); $\Delta$ R/R was $19.94 \pm 2.01 \%$ (Fig. 3F), values not significantly different from GN11 cells.

The picture was markedly different for the 994-D4 clone (Fig. 3C). The percentage of cells expressing functional VDCCs was significantly higher $(91.56 \pm 3.89 \%, \mathrm{p}<0.05$; post-hoc Tukey's test; 154 cells, 4 experiments; Fig. 3E). Moreover, also $\Delta \mathrm{R} / \mathrm{R}$ of the responding cells was 
significantly higher $(39.11 \pm 3.43 \%, \mathrm{p}<0.01$ post-hoc Tukey's test $)$ than in the control and scrambled ones (Fig. 3F), indicative of a greater density of VDCCs.

As a comparison, $\mathrm{KCl}$-induced increases in $\left[\mathrm{Ca}^{2+}\right]_{\mathrm{i}}$ were recorded also in GT1-7 cells (273 cells, 5 experiments; Fig. 3D). The percentages of responding cells (86.12 \pm 4.30 ; Fig. 3E) and the amplitude of responses $(\Delta \mathrm{R} / \mathrm{R}=38.24 \pm 6.91$; Fig. $3 \mathrm{~F})$ were not significantly different from those obtained for the D4-994 clone.

In order to identify the nature of the channels involved, we performed a set of tests with blockers of VDCCs, starting with $\omega$-agatoxin IVA, a selective blocker of P/Q channels, whose transcripts have been reported to be present in this cell line [22]. For these experiments, we focused on GN11 and 994-D4 cells; only responding cells, with $\Delta \mathrm{R} / \mathrm{R}>0.1$, were investigated.

Unexpectedly, in GN11 cells the responses to $40 \mathrm{mM} \mathrm{KCl}$ were only partially reduced (to $46.3 \pm$ $4.2 \%$ of control) by the P/Q blocker (200 nM; 57 cells, 4 experiments; Fig. 4A, C). When cells were perfused with nifedipine $(10 \mu \mathrm{M})$, a blocker of L-type VDCCs, a reduction to $38.4 \pm 1.7 \%$ of the control response was observed (110 cells, 4 experiments, Fig. 4A, C). Preincubation with both blockers completely abolished the response to the high $\mathrm{KCl}$ solution (Fig. 4A, inset).

The 994-D4 clone gave a different picture: $\omega$-agatoxin IVA induced a stronger reduction in response amplitude to $38.9 \pm 1.8 \%$ of control (92 cells, 3 experiments, Fig. 4B, C); on the other hand nifedipine caused a smaller reduction (to $89.6 \pm 5.5 \%$ of control; 50 cells, 3 experiments, Fig. 4B, C). Again, preincubation with both blockers completely abolished the response to high $\mathrm{KCl}$ (Fig. 4B, inset). In some experiments (see Fig 4A) the high $\mathrm{KCl}$ control solution was administered both before and after the solution containing the blockers, to check that the control response was not affected by the previous perfusion with the blockers.

\section{L- and P/Q-type channel expression}

Based on the above results, we analyzed expression levels of the various VDCCs, both at the transcript and at the protein level. Supplementary Fig. SM 2 shows the results of quantitative PCR analysis of the transcripts of the major classes of VDCCs: Cav1.2, 1.3 (L-type), $2.1(\mathrm{P} / \mathrm{Q}), 2.2(\mathrm{~N})$ and $3.2(\mathrm{~T})$ channels. Interestingly, and at variance with the data reported in [22], all are expressed both in the control and in the silenced line. A threefold increase of Cav1.2 and a slight but significant decrease of Cav1.3 and Cav3.2 was detected in the 994-D4 line as compared to GN11 cells, while for other two channel types no significant change in the level of the transcripts could be detected. We then performed a Western Blot analysis of protein levels for L-and P/Q-type channels, that contribute to virtually $100 \%$ of the responses to high $\mathrm{KCl}$, and for the T-type channel, given the change in transcript levels between the two lines. Fig. 4D-G shows a representative experiment out of three for each channel type. As for L-and P/Q channels, in GN11 cells all three channel proteins 
were detected; on the other hand, in the 994-D4 clone the expression pattern showed marked differences. $\mathrm{Ca}_{\mathrm{V}} 2.1$ levels were significantly higher (100\% in 994-D4 cells compared to $51 \pm 4.5 \%$ in GN11 cells, p < 0.05, t-test; Fig, 4D). Cav1.2 was not substantially altered (92.6 $\pm 2.4 \%$ expression level in GN11cells compared to $100 \%$ in 994-D4 cells, Fig. 4E), while Cav1.3 expression was not evidenced (Fig. 4F). Moreover, as shown in Fig. 4G, the T-type channel protein was not detected either in GN11 or in 994-D4 cells, while it was present in GT1-7 cells, that have been shown to possess functional T-type channels [23]. Therefore, proteins levels are not univocally related to transcript levels, and this is not unexpected, given the complex regulatory pathways controlled by REST, both at the transcriptional and post-transcriptional level [3]. Finally, the effect of the two blockers on the migratory activity of the two lines were tested: combined application of nifedipine $(10 \mu \mathrm{M})$ and $\omega$-agatoxin IVA $(200 \mathrm{nM})$ significantly reduced migration of both wild type GN11 and 994-D4 cells. However, a different sensitivity to the two blockers was observed (see Supplementary Materials Fig. SM 3).

\section{Discussion}

In this paper we provide the first evidence that in GN11 cells, representing a model of early stage, rather undifferentiated GnRH neurons, REST modulates the migratory behavior and the expression of voltage dependent calcium channels.

The fact that REST levels are related to the differentiation stage of GnRH neurons is highlighted by the observation that in a more differentiated line derived from hypothalamic GnRH neurons, GT1-7 cells, REST levels are markedly lower than in GN11 cells. This difference between the two lines, that could be fully eliminated by the silencing approach, prompted us to investigate the role of the factor in the control of the expression of voltage dependent calcium channels, that control key functional aspects of neuronal excitability and motility.

Our data show, for the first time, that a significant subpopulation of GN11 cells possesses the transcripts of the major classes of VDCCs (L, P/Q, N, T-type) but only two types are expressed at the functional level, even if at low densities: not only P/Q channels [22], but also L channels. Down-regulation of REST increases the percentage of cells expressing functional VDCCs and the density of these channels at the single cell level. Immunoblotting and pharmacological experiments point to a strong enhancement of expression of $\mathrm{Ca}_{\mathrm{V}} 2.1$ (P/Q-type) channels. This finding is in agreement with an earlier report [24] that the CACNA1A gene, encoding for these channels, is strongly repressed by REST. For L-type channels, the effects are less obvious, with absence of the $\mathrm{Ca}_{\mathrm{V}} 1.3$ protein in the silenced clone, while $\mathrm{Ca}_{\mathrm{V}} 1.2$ levels are unaffected. The data on $\mathrm{Ca}_{\mathrm{V}} 1.3$ channels is at partial variance with previous data [13] showing that $\mathrm{Ca}_{\mathrm{V}} 1.3$ is repressed in a high- 
REST PC12 clone, expressing a 40-fold increase in REST transcript over the parental line, while in a second clone, showing a 180-fold increase, it is not. Therefore, the relationship between REST levels and expression of putative target genes is not straightforward, and the outcome may depend on the specific cellular context. The complexity of the regulatory mechanisms orchestrated by REST is reflected also in our data on the Cav3.2 channel; the CACNA1H gene, encoding for this channel, has been reported to be repressed by REST [25]: actually we found a slight reduction in transcript levels in 994-D4 cells, without any functional effect, since the protein was not detected either in GN11 or in 994-D4 cells.

Another relevant feature of immature neurons is the high migratory potential. Here we show that REST silencing significantly reduces cell motility to levels comparable with those of GT1-7 cells, thus providing additional evidence for the appearance of a more mature phenotype. In both wildtype and silenced cells the migratory activity is dependent at least partially from VDCCs; REST silencing shifts the dependence from L- to P/Q-type channels.

Taken together, our findings provide the first evidence of the role of the transcriptional repressor REST in the control of calcium signaling mechanisms and migratory potential in a consolidated model of early stage GnRH neurons.

\section{Acknowledgements}

Thanks to Dr. Davide Pozzi (Humanitas Clinical and Research Center, Milano, Italy) for giving us the shRNA constructs, to Dr. Paolo Giacobini (Inserm, Lille, France) and Prof. Jacopo Meldolesi (San Raffaele Institute, Milano, Italy) for suggestions and discussions, to Prof. Giorgio Gribaudo, Dr. Daniela Gavello and Dr. Roberta Bardini for technical help. GT1-7 cells were the generous gift of Prof. P. Mellon, UCSD, USA. Research performed thanks to the institutional funds of the University of Torino.

\section{Author Contributions}

Conceived and designed the experiments: SA, DL. Performed the experiments: RD, FAR, SA, AL, ST. Analyzed the data: FAR, SA. Wrote the paper: DL, SA. 


\section{References}

[1] J.A. Chong, J. Tapia-Ramírez, S. Kim, J.J. Toledo-Aral, Y. Zhen et al., REST: a mammalian silencer protein that restricts sodium channel gene expression to neurons, Cell 80 (1995) 949-957.

[2] C.J. Schoenherr, D.J. Anderson, The neuron-restrictive silencer factor (NRSF): a coordinate repressor of multiple neuron-specific genes, Science 267 (1995) 1360-1363.

[3] I.A. Qureshi, M.F. Mehler, Regulation of non-coding RNA networks in the nervous system-what's the REST of the story?, Neurosci. Lett. 466 (2009) 73-80.

[4] X. Su, S. Kameoka, S. Lentz, S. Majumder, Activation of REST/NRSF target genes in neural stem cells is sufficient to cause neuronal differentiation, Mol. Cell Biol. 24 (2004) 8018-8025.

[5] R. D'Alessandro, A. Klajn, L. Stucchi, P. Podini, M.L. Malosio et al., Expression of the neurosecretory process in PC12 cells is governed by REST, J. Neurochem. 105 (2008) 1369-1383.

[6] N. Ballas, C. Grunseich, D.D. Lu, J.C. Speh, G. Mandel, REST and its corepressors mediate plasticity of neuronal gene chromatin throughout neurogenesis, Cell 121 (2005) 645-657.

[7] Z. Gao, K. Ure, P. Ding, M. Nashaat, L. Yuan et al., The master negative regulator REST/NRSF controls adult neurogenesis by restraining the neurogenic program in quiescent stem cells, $\mathrm{J}$.

Neurosci. 31 (2011) 9772-9786.

[8] A. Calderone, T. Jover, K.M. Noh, H. Tanaka, H. Yokota et al., Ischemic insults derepress the gene silencer REST in neurons destined to die, J. Neurosci. 23 (2003) 2112-2121.

[9] K.M. Noh, J.Y. Hwang, A. Follenzi, R. Athanasiadou, T. Miyawaki et al., Repressor element-1 silencing transcription factor (REST)-dependent epigenetic remodeling is critical to ischemiainduced neuronal death, Proc. Natl. Acad. Sci. USA 109 (2012) E962-971.

[10] S. McClelland, G.P. Brennan, C. Dubé, S. Rajpara, S. Iyer et al., The transcription factor NRSF contributes to epileptogenesis by selective repression of a subset of target genes. Elife Aug 12;3:e01267 (2014).

[11] D. Pozzi, G. Lignani, E. Ferrea, A. Contestabile, F. Paonessa et al., REST/NRSF-mediated intrinsic homeostasis protects neuronal networks from hyperexcitability, EMBO J. 32 (2013) 29943007.

[12] Z.F. Chen, A.J. Paquette, D.J. Anderson, NRSF/REST is required in vivo for repression of multiple neuronal target genes during embryogenesis, Nat. Genet. 20 (1998) 136-142.

[13] A.W. Bruce, A. Krejcí, L. Ooi, S.J. Deuchar, I.C. Wood et al., The transcriptional repressor REST is a critical regulator of the neurosecretory phenotype, J. Neurochem. 98 (2006) 1828-1840.

[14] P. Ariano, P. Zamburlin, R. D'Alessandro, J. Meldolesi, D. Lovisolo, Differential repression by the transcription factor REST/NRSF of the various $\mathrm{Ca}^{2+}$ signalling mechanisms in pheochromocytoma PC12 cells, Cell Calcium 47 (2010) 360-368.

[15] S. Wray, A. Nieburgs, S. Elkabes, Spatiotemporal cell expression of luteinizing hormonereleasing hormone in the prenatal mouse: evidence for an embryonic origin in the olfactory placode, Brain Res. Dev. Brain Res. 46 (1989) 309-318.

[16] S. Wray, Development of luteinizing hormone releasing hormone neurons, J. Neuroendocrinol. 13 (2001) 3-11. 
[17] S. Radovick, S. Wray, E. Lee, D.K. Nicols, Y. Nakayama et al., Migratory arrest of gonadotropin-releasing hormone neurons in transgenic mice, Proc. Natl. Acad. Sci. USA 88 (1991) 3402-3406.

[18] F. Pimpinelli, E. Redaelli, R. Restano-Cassulini, G. Curia, P. Giacobini et al., Depolarization differentially affects the secretory and migratory properties of two cell lines of immortalised luteinizing hormone-releasing hormone (LHRH) neurons, Eur. J. Neurosci. 18 (2003) 1410-1418.

[19] C. D'Orlando, F. Guzzi, M. Gravati, G. Biella, M. Toselli et al., Retinoic acid- and phorbol ester-induced neuronal differentiation down-regulates caveolin expression in GnRH neurons, J. Neurochem. 104 (2008) 1577-1587.

[20] P.L. Mellon, J.J. Windle, P.C. Goldsmith, C.A. Padula, J.L. Roberts et al., Immortalization of hypothalamic GnRH neurons by genetically targeted tumorigenesis, Neuron 5 (1990) 1-10.

[21] Y. Toba, J.G. Pakiam, S. Wray, Voltage-gated calcium channels in developing GnRH-1 neuronal system in the mouse, Eur. J. Neurosci. 22 (2005) 79-92.

[22] U. Storch, A.L. Forst, M. Philipp, T. Gudermann, M. Mederos y Schnitzler, Transient receptor potential channel 1 (TRPC1) reduces calcium permeability in heteromeric channel complexes, J. Biol. Chem. 287 (2012) 3530-3540.

[23] A. Gilardino, F. Catalano, F.A. Ruffinatti, G. Alberto, B. Nilius et al., Interaction of SiO2 nanoparticles with neuronal cells: Ionic mechanisms involved in the perturbation of calcium homeostasis, Int. J. Biochem. Cell Biol. 66 (2015) 101-111.

[24] R. Johnson, R.J. Gamblin, L. Ooi, A.W. Bruce, I.J. Donaldson et al., Identification of the REST regulon reveals extensive transposable element-mediated binding site duplication, Nucleic Acids Res. 34 (2006) 3862-3877.

[25] K.M. van Loo, C. Schaub, K. Pernhorst, Y. Yaari, H. Beck et al., Transcriptional regulation of T-type calcium channel CaV3.2: bi-directionality by early growth response 1 (Egr1) and repressor element 1 (RE-1) protein-silencing transcription factor (REST), J. Biol. Chem. 287 (2012) 1548915501. 


\section{Figure legends}

\section{Figure 1 - REST expression in GN11 and GT1-7 cell lines.}

A. REST expression levels in total protein lysates from GN11 and GT1-7 cells. Percentage values reported at the bottom correspond to the amount of REST protein present in each lane, referred to GN11 cells, lane 2. B. REST expression levels in total protein lysates from wild type GN11, scramble (SCR) and 994-D4 cells. Percentage values refer to GN11 cells, lane 1.

\section{Figure 2 - GN11 migration is reduced in the REST knock-down clone.}

Evaluation of cell migration by scratch assay. After making the scratch (width $=100 \%$ ), the distance covered was evaluated at different time points for GN11 cells, (293 scratches), scramble cells, (287 scratches), 994-D4 cells (279 scratches) and GT1-7 cells (298 scratches). No significant differences could be detected between GN11 and scramble cells; on the other hand distances covered by $994-D 4$ and GT1-7 were significantly lower at every time point ( ${ }^{*}$ p $<0.05$ vs GN11 and scramble). The migratory rate of 994-D4 cells, even if reduced, was still significantly higher than for GT1-7 cells $(\S \mathrm{p}<0.05)$.

Figure 3 - Depolarization-induced changes in $\left[\mathrm{Ca}^{2+}\right]_{\mathrm{i}}$ are enhanced in the low-REST clone. Increases in $\left[\mathrm{Ca}^{2+}\right]_{\mathrm{i}}$ induced by chemical depolarization with $40 \mathrm{mM} \mathrm{KCl}$. A. wild type GN11 cells (average of 43 responsive cells, one experiment representative of four). B. scramble cells (average of 29 responsive cells, one of six experiments). C. 994-D4 clone (average of 33 responsive cells, one of four experiments). D. GT1-7 cells (average of 58 responsive cells, one of five experiments). E. Percentages of responsive cells for GN11, scramble, 994-D4 and GT1-7 cells. *p<0.05. F. $\Delta$ R/R values from responsive cells from the four lines as in $\mathrm{E} .{ }^{*} \mathrm{p}<0.05$.

Figure 4 - Functional expression of VDCCs subtypes and their contribution to high KClinduced increase in $\left[\mathrm{Ca}^{2+}\right]_{i}$ in wild type and silenced cells.

Effect of blockers of VDCCs on $\mathrm{KCl}$-induced increases in $\left[\mathrm{Ca}^{2+}\right]_{\mathrm{i}}$. A. Reduction of the response to $40 \mathrm{mM} \mathrm{KCl}$ in GN11 cells by the P/Q channel blocker $\omega$-agatoxin IVA, $200 \mathrm{nM}$ (upper; averaged response from 9 responsive cells, one experiment representative of four) and by the L channel blocker nifedipine, $10 \mu \mathrm{M}$ (lower; averaged response from 10 responsive cells, one experiment representative of four). Inset: combined perfusion with both blockers completely abolished the response to high $\mathrm{KCl}$ (14 cells; one experiment representative of three). B. Reduction of the response to $40 \mathrm{mM} \mathrm{KCl}$ in 994-D4 cells by $\omega$-agatoxin IVA, $200 \mathrm{nM}$ (upper; averaged response 
from 15 responsive cells, one experiment representative of three) and by nifedipine, $10 \mu \mathrm{M}$ (lower; averaged response from 15 responsive cells, one experiment representative of three). Inset: combined perfusion with both blockers completely abolished the response to high $\mathrm{KCl}$ ( 16 cells, one experiment representative of three). C. Summary of the effects of the blockers on the two cell lines, expressed in terms of relative reduction respect to the control (high $\mathrm{KCl}$ without blockers, corresponding to $100 \%)$. ${ }^{*} \mathrm{p}<<0.01,{ }^{*} \mathrm{p}<0.05$. D.-G. Expression of the channel subtypes in GN11 and 994-D4 cells. A typical blot is shown for each VDCC (representative experiment out of three for each channel type): $\mathrm{Ca}_{\mathrm{V}} 2.1$ for P/Q-type channels (D), Ca 1.2 (E) and $\mathrm{Ca}_{\mathrm{V}} 1.3$ (F) for L-type, $\mathrm{Ca}_{\mathrm{V}} 3.2$ (G) for T-type. While $\mathrm{Ca}_{\mathrm{V}} 1.3$ could not be detected in 994-D4 cells, Cav1.2 expression levels were similar in both cell types; on the contrary, expression of $\mathrm{Ca}_{\mathrm{V}} 2.1$ was significantly increased in 994-D4 clone as compared to GN11 cells. Cav3.2 was not detected in both lines, while it was expressed in GT1-7 cells. 

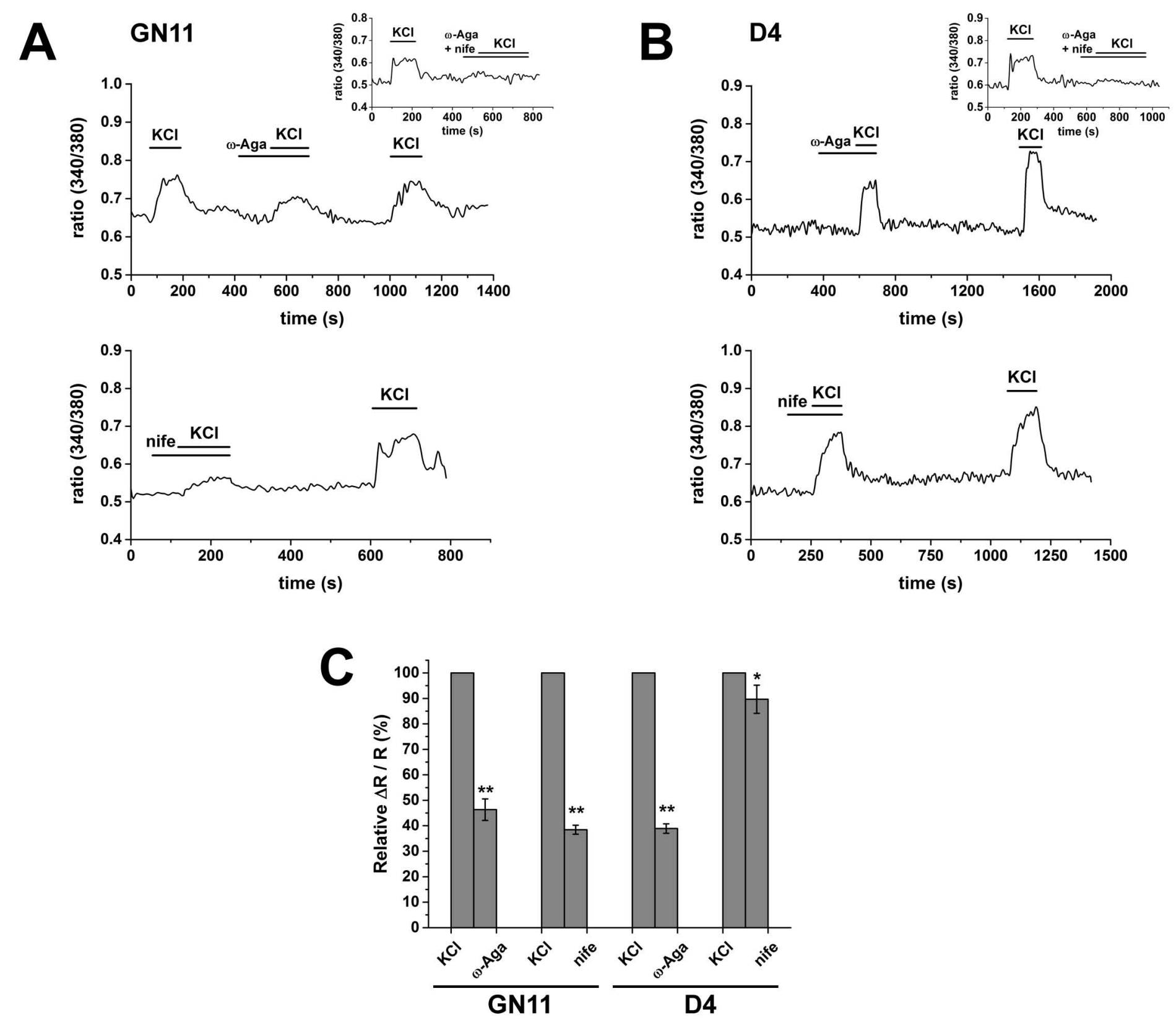

D

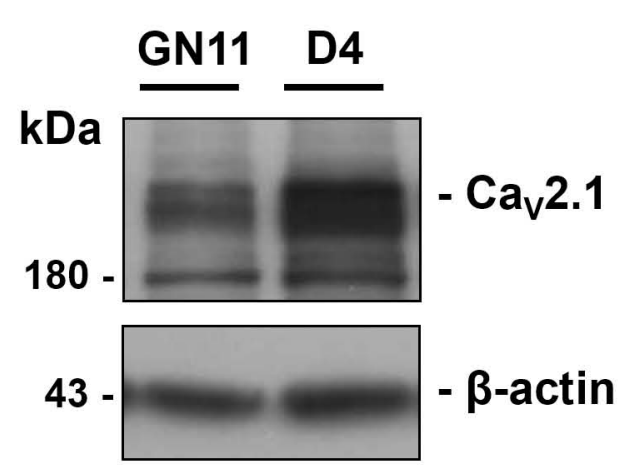

E
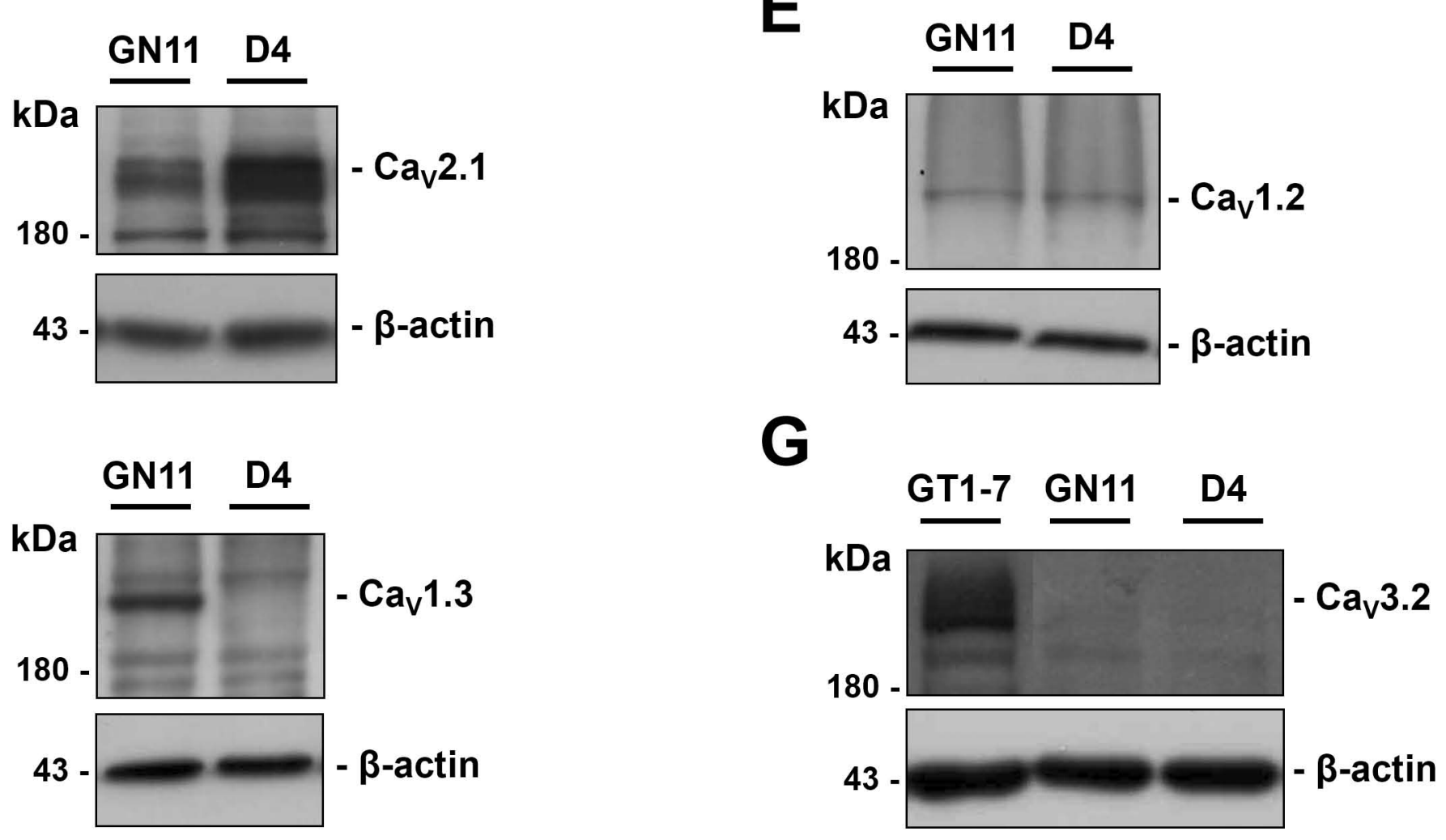

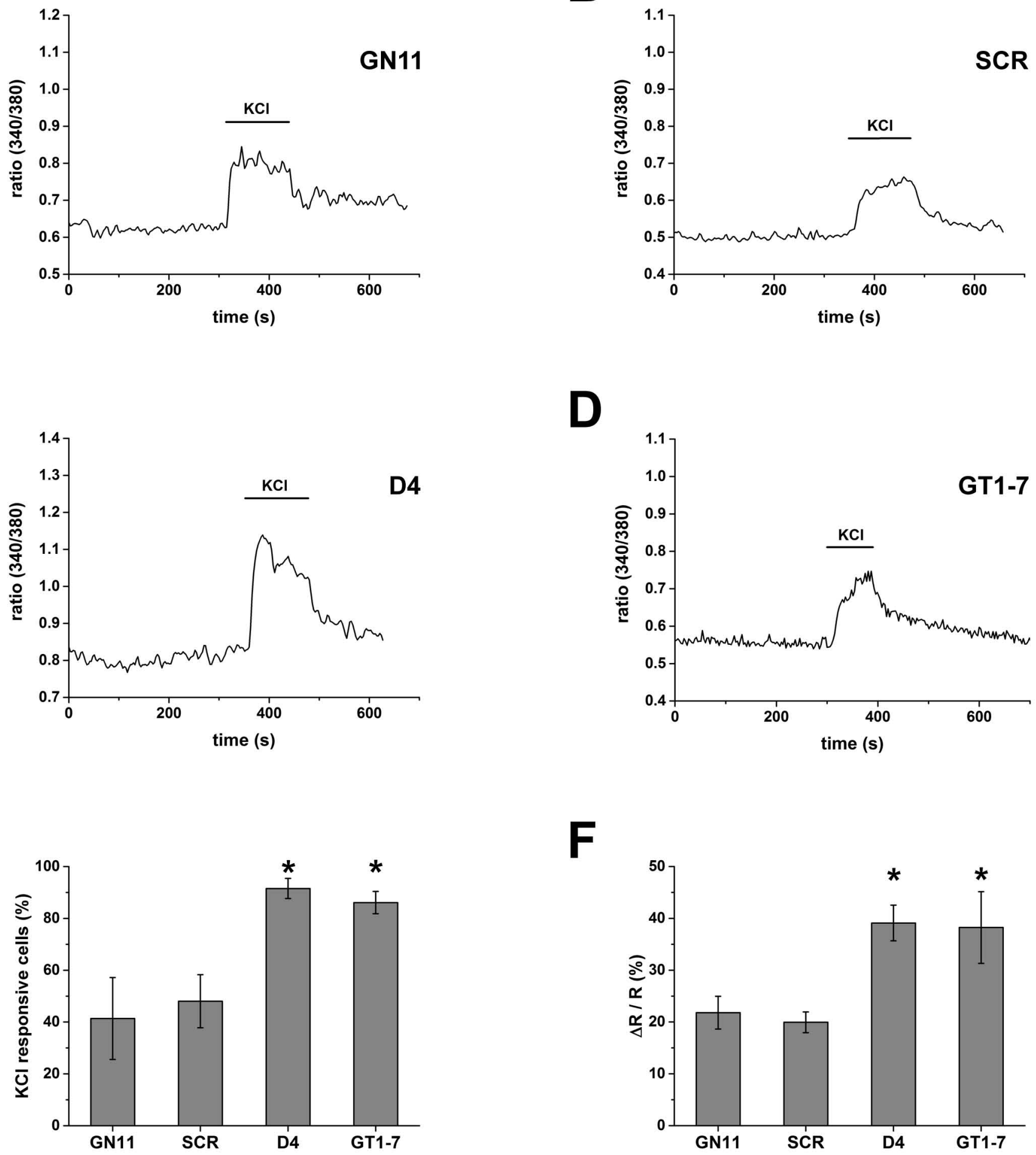


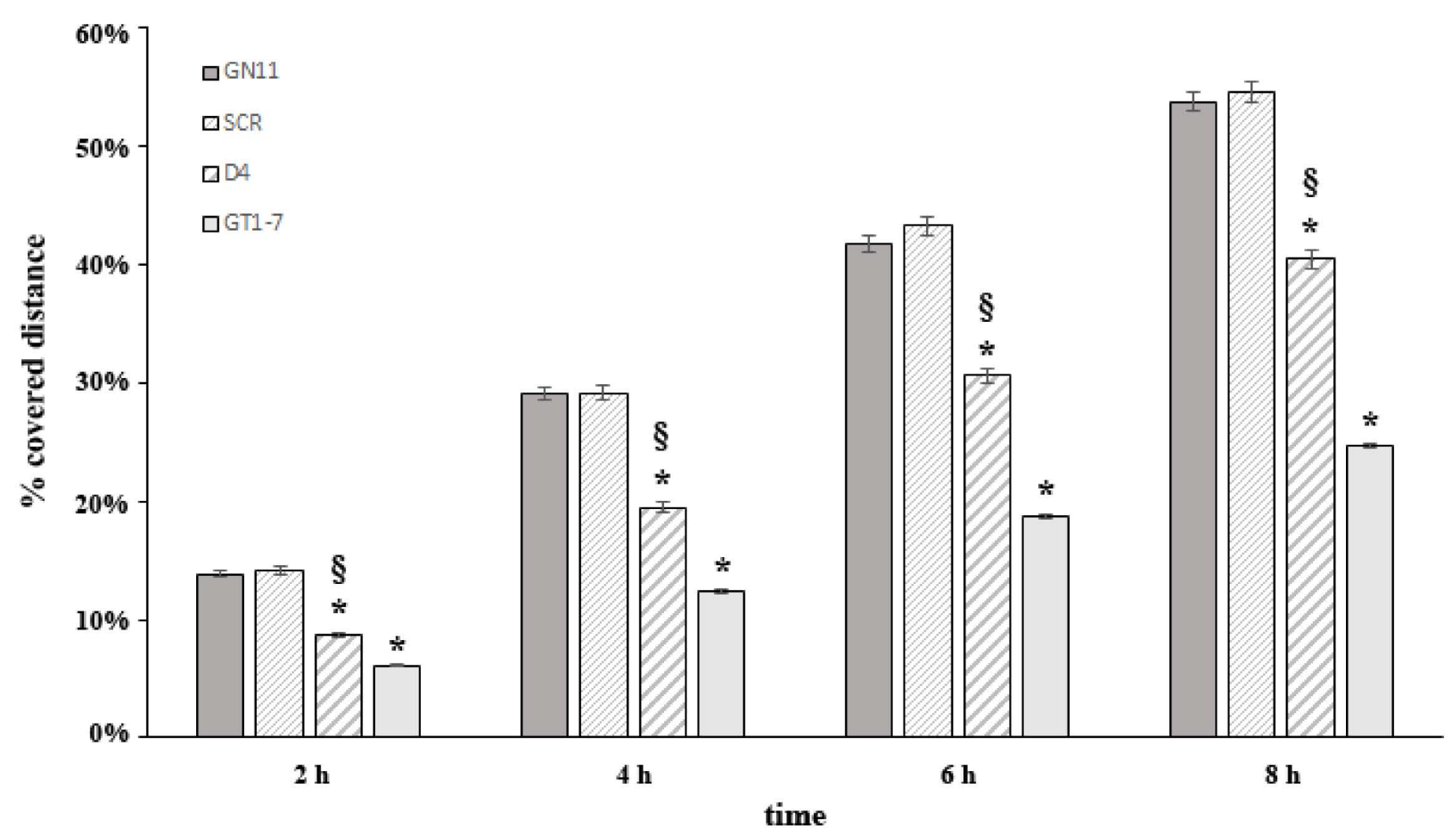




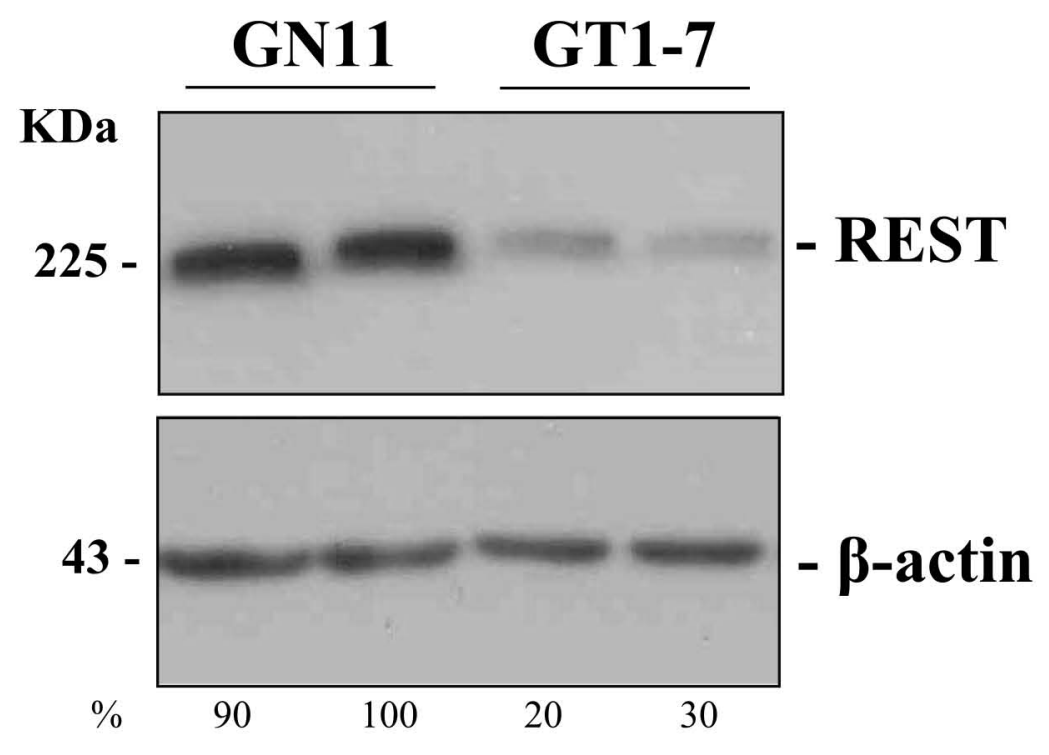

GN11 SCR $\quad$ D4

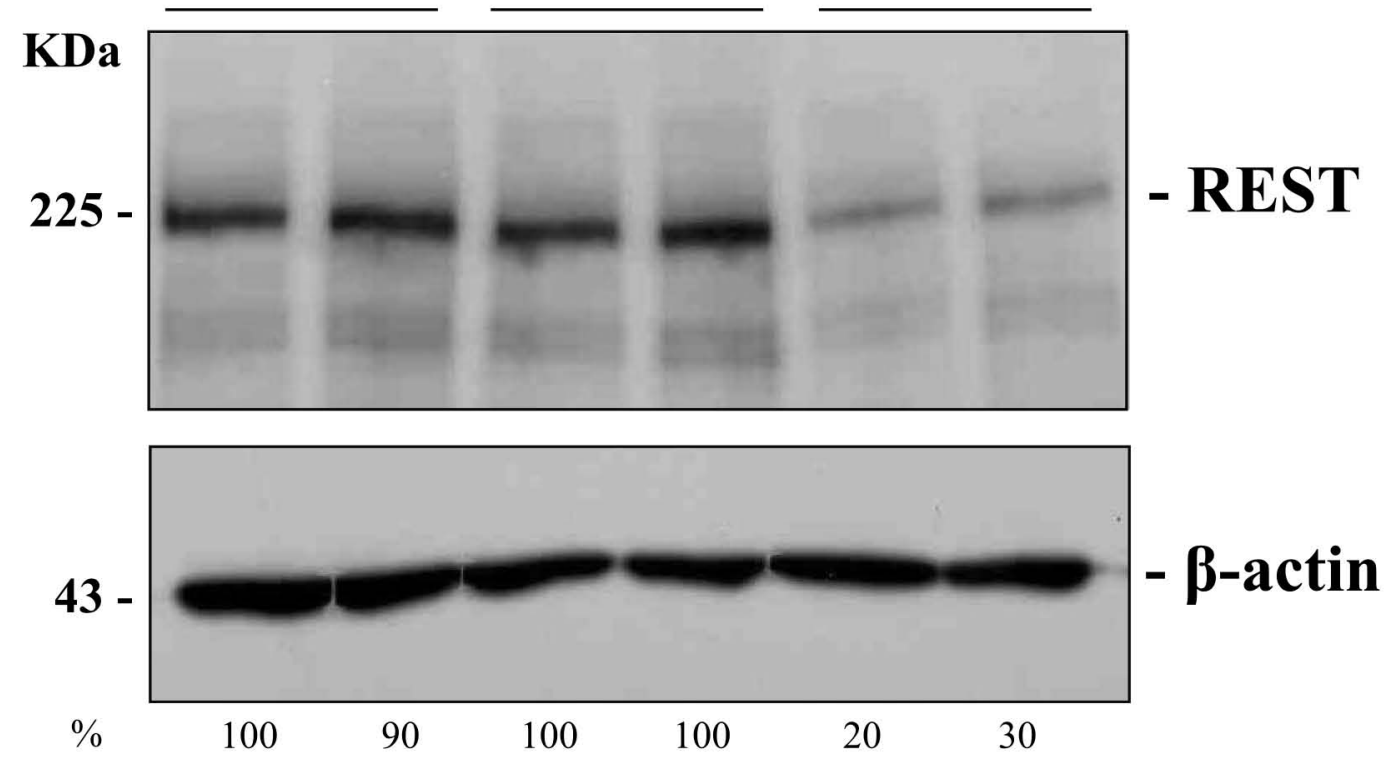

